\title{
EDIÇÃO DOS SERMÕES DE DOM FREI DOMINGOS DA TRANSFIGURAÇÃO MACHADO DO MOSTEIRO DE SÃO BENTO DA BAHIA
}

\author{
Marília Andrade Nunes (UFBA; MSB-BA) \\ nunes.mandrade@gmail.com \\ Alícia Duhá Lose (UFBA; MSB-BA) \\ alicialose@gmail.com
}

\section{Introdução}

Como já afirmara Erich Auerbach (1972,p. 11),

A filologia é o conjunto das atividades que se ocupam metodicamente da linguagem do homem e das obras de arte escritas nessa linguagem. Como se trata de uma ciência muito antiga, e como é possível ocupar-se da linguagem de diferentes maneiras, o termo filologia tem um significado muito amplo e abrange atividades assaz diversas.

A filologia também é a área que se ocupa do estudo de manuscritos que guardam a história da civilização. Essa ciência surgiu com os eruditos da biblioteca de Alexandria e se divide em dois ramos: um trabalha com a história da língua e suas mudanças (linguística histórica) e o outro trabalha com a história do texto (crítica textual), dois universos indissociáveis.

Os objetivos e metodologia dos dois ramos são interdependentes, pois a análise da língua é fundamental para o estabelecimento do texto crítico, assim como uma boa edição de um texto traz para o estudo linguístico a língua mais próxima possível de sua realidade histórica. A crítica textual utiliza a linguística para estudar os textos e a linguística utiliza os textos para descrever a língua. Há, então, uma relação de troca e dependência entre os dois ramos da filologia, um sempre servindo de base para a elaboração do outro. (TELLES, 2000)

É sabido que a crítica textual tem como objetivo principal buscar, através da edição, o texto mais fidedigno. Desta forma, resgata e traz para a modernidade o testemunho histórico e documental de uma época, fazendo com que a sociedade tenha uma compreensão melhor de sua história. Além disso, visa a permitir que os textos antigos manuscritos sejam passíveis de estudo e análise de profissio- 
nais das mais diversas áreas de conhecimento não especializadas nas técnicas de leitura de manuscritos, como direito, arquitetura, história, geografia, arqueologia e todas as demais que o conteúdo do documento possa interessar.

\section{Problemática}

A filologia, desta forma, não é apenas a investigação do instrumento linguístico como tal, apesar de utilizá-lo para penetrar nos textos construídos em determinadas línguas, com o objetivo de restaurar, depurar e interpretar estes textos, que já não são necessariamente literários. Assim, segundo Cano Aguilar (2000), a filologia segue como auxiliar e ao mesmo tempo como apoio a diversas outras disciplinas, perdendo sua pretensão de onipresença.

Neste sentido, como sempre aconteceu, os estudos filológicos andam de braços dados com os estudos linguísticos, abrindo espaço para textos não literários, e não tomando para si a tarefa dos estudos de língua como elemento primeiro, que, no entanto, continua sendo visto como indissociável para a penetração no conteúdo do texto.

O objeto deste trabalho são alguns dos Sermões deixados por dom frei Domingos da Transfiguração Machado. Tais textos, que representam apenas uma parte do importante acervo documental deixado por frei Domingos, se consistem num conjunto de, em sua maioria, manuscritos e alguns datiloscritos, que apresentam sermões, exortação com finalidade doutrinária, que são acompanhados do discurso (pregação), que se compõem de uma reflexão sobre o conteúdo de tais textos e busca relacioná-los à realidade dos fiéis; assim, ajuda os cristãos a compreender e viver os ensinamentos bíblicos. Os sermões em questão foram escritos no século XIX por um monge que tem importância ímpar na história da Congregação Beneditina do Brasil.

Dom frei Domingos da Transfiguração Machado nasceu na grande ilha de Itaparica, situada à entrada da Baía de Todos os Santos, ingressou no Mosteiro de São Bento em 13 de junho de 1842, e em 20 de outubro de 1847 recebeu o diaconato e o presbiterato. O dia 3 de dezembro de 1847 ficou indelevelmente gravado na memória de Dom Frei Domingos, pois nesta data foi ordenado. Celebraria 
em 1907, 60 anos depois, o seu jubileu sacerdotal de diamantes (SCHERER, 1980, p. 19, 24 e 27). Graças ao empenho de dom frei Domingos da Transfiguração Machado, a Congregação Beneditina foi restaurada no Brasil entre o final do século XIX e início do século XX.

Os Sermões de dom frei Domingos estão organizados em dezenove cadernos manuscritos e um datiloscrito, tendo sido todos acondicionados em uma caixa cujo formato assemelha-se ao de um livro.

Os cadernos dos Sermões manuscritos são, em sua maioria, costurados, mas em alguns casos esta costura já está se soltando. Todos eles estão envoltos em um papel amarelado, de gramatura alta, onde está escrito com lápis de cera azul "Sermões de Frei Domingos da Transfiguração Machado" e, com lápis de cera vermelho, tem-se "Nota: De Fr. Domingos parece ser só o que ele mesmo diz ser o primeiro, pregado 13/XII/1837 por ocas. da $1^{a}$ Missa de Fr. Ignacio de S. Paio resta identificar os aqui reunidos" Os documentos em si (cada sermão), estão escritos em tinta ferrogálica, que, em muitos fólios, devido ao excesso de fixador, terminou corroendo o papel, o que dificulta a leitura, visto que a maioria dos fólios está escrita em recto e verso. O papel da maioria dos fólios tem gramatura média e é pouco poroso, apresenta marca de dobra bem no centro, no sentindo vertical, mas não apresenta marca d'água. Existem poucas anotações marginais, mas alguns fólios apresentam muitas rasuras e acréscimos. O caderno datiloscrito apresenta o título "Sermão de Santa Luzia" e possui oito fólios escritos somente no recto. O papel é fino, pouco poroso e amarelado.

De modo geral, os fólios estão em bom estado de conservação. Aparentemente, não há continuação de um caderno para outro, sendo eles, então, organizados de maneira aleatória. Alguns apresentam título, outros não.

Esses documentos encontram-se no Arquivo do Mosteiro de São Bento da Bahia, que, junto com a Biblioteca Histórica do Mosteiro de São Bento da Bahia e o seu Centro de Documentação e Pesquisa do Livro Raro, é tombado pelo Instituto do Patrimônio Histórico e Artístico Nacional (IPHAN), por possuir um importante acervo de obras raras e antigas. 
O mosteiro está situado no centro da cidade de Salvador e é o primeiro mosteiro beneditino das Américas. Fundado em 1582, sua importância supera o âmbito histórico, pois os monges beneditinos, além de serem coparticipantes da construção da história da Bahia e do Brasil, estão plenamente inseridos no desenvolvimento local e regional através da promoção e preservação das artes, da cultura e do saber.

\begin{abstract}
O Mosteiro não apenas é o guardião de um acervo bastante raro (pinacoteca, biblioteca, mobiliário, imaginária, ourivesaria, arquitetura), mas foi palco, cenário e personagem de inúmeros acontecimentos importantes para a história da Bahia e em especial para a cidade de Salvador. Contribuiu de modo decisivo para a expansão urbana da capital baiana e atuou em diversas frentes de trabalho no sentido de proporcionar o seu desenvolvimento intelectual por meio de sua atividade na área da educação básica (Colégio São Bento) e superior (Faculdade de Filosofia e Teologia). Desde a fundação do Mosteiro da Bahia, conforme as informações históricas que se encontram nos arquivos da Ordem de São Bento em Portugal, os monges beneditinos da Bahia dedicaram-se ao trabalho na área das Letras e a pesquisa filológica e histórica feitas de maneira empírica. (ANDRADE; LOSE, 2007)
\end{abstract}

Sua biblioteca conserva um grande acervo de obras raras e seu Arquivo um importante acervo de documentos manuscritos, dentre os quais se encontram: bulas papais, cartas de profissão dos monges, sermões, documentos relativos à vida privada do mosteiro, documentação relativa às propriedades de toda a região metropolitana de Salvador e livros de pedidos de oração.

Para este projeto, estudar-se-ão os seguintes sermões: "Sobre o escândalo", "Sobre a maledicência", "Paixão", "Sermão da Misericórdia", "Nossa Senhora de Montserrat" e "São Sebastião".

\title{
3 Problema
}

A partir desses documentos, pretende-se, portanto, proceder a um estudo em nível exploratório (o que exime a presença de hipóteses) que terá como base duas questões norteadoras (GOMES; LOSE, 2007):

a) que critérios seriam mais adequados para elaboração de uma edição que apresentasse o texto dos sermões, todos constituídos de esboços ou rascunhos, em uma leitura aprazível ao 
público leigo, interessado prioritariamente no "conteúdo exortativo religioso", demonstrando, no entanto, fielmente todas as características da escrita do texto original?

b) que dados linguísticos, no que tange ao léxico, podem ser observados nesses documentos que caracterizem este discurso?

\section{Objetivo geral}

A presente proposta objetiva oferecer o texto dos sermões "Sobre o escândalo", "Sobre a maledicência", "Paixão", "Sermão da Misericórdia", "Nossa Senhora de Montserrat" e "São Sebastião" de dom frei Domingos da Transfiguração Machado através de uma edição que apresente o que "teria sido" a sua versão definitiva, sem que se percam as características linguísticas presentes no original.

\section{Objetivos específicos}

Para tal pretende-se:

a) analisar extrínseca e intrinsecamente todos os documentos selecionados;

b) revisar a edição semidiplomática anteriormente preparada;

c) depurar o texto das marcas gráficas utilizadas na edição conservadora;

d) elaborar critérios que permitam apresentar o texto no que "seria" a sua versão definitiva;

e) proceder a uma análise linguística referente ao discurso presente nos textos;

f) preparar a edição em uma linguagem adequada ao público leigo para que este possa se beneficiar do conteúdo dos textos em questão. 


\section{Justificativa}

Último abade geral, dom Domingos da Transfiguração Machado foi o responsável pela restauração da Congregação Beneditina do Brasil. Com 33 anos ocupou o cargo de presidente do Priorado de Santos. Nesta função, reconstruiu o mosteiro e restaurou a igreja, trabalho elogiado pelo $2^{\circ}$ visitador da Congregação, frei José de Santa Maria Amaral. De regresso à Bahia foi nomeado secretário do abade geral, no período de 1878 a 1881, exercendo também as funções de mordomo (responsável pelas obras de construção) e mestre de oblatos. Em 8 de maio de 1866, foi eleito prior do mosteiro da Bahia. No período de 1881-1884, foi procurador da Congregação Beneditina Brasileira.

Como $1^{\circ}$ visitador (1884-1890) teve ocasião de conhecer a fundo o estado precário da Congregação Beneditina do Brasil. No Capítulo Geral da Congregação, realizado em 07 de maio de 1890, foi eleito abade geral. Este estado precário da Congregação era reflexo de uma forte crise sociopolítico-religiosa existente na ocasião. Com efeito, um aviso ministerial do governo de 13 de maio de 1855 , proibia a recepção de noviços e a tentativa de formar novos monges no exterior foi interditada pelo Governo no dia 27 de outubro de 1870 .

O abade frei Jesuíno da Conceição já estava de posse de uma petição do Vaticano sugerindo que o Mosteiro de São Paulo, juntamente com o seu patrimônio, fosse cedido ao Bispo diocesano para que fosse transformado num educandário destinado "às filhas das famílias mais ricas da cidade".

Nesta situação, quando o frei Jesuíno abriu o capítulo para a eleição do seu sucessor, disse: "Com grande tristeza devo dizer, como bem o sabeis, que a nossa ordem se acha ameaçada de todos os lados. Nas atuais circunstâncias, como vai ser triste e doloroso o pouco tempo que ainda nos resta de vida." (AMARAL, 2006) Foi neste contexto que o abade geral dom frei Domingos da Transfiguração entendeu a missão que teria pela frente de não deixar desaparecer das terras do Brasil a vida monástica e o primeiro mosteiro das Américas, o Mosteiro de São Bento da Bahia. 
Após a queda do império brasileiro, o abade frei Domingos pede ao papa Leão XIII, monges para retomarem a vida monástica brasileira que estava quase no fim. Os primeiros monges chegaram ao Mosteiro de Olinda em 1895 e no Mosteiro da Bahia em 1898. Nesse mesmo ano o Papa Leão XIII, em consideração aos merecimentos de dom frei Domingos da Transfiguração pelo grande zelo e esforço em prol da restauração da Congregação Beneditina Brasileira e com a finalidade de consolidar essa obra, concedeu-lhe a perpetuidade no cargo de abade geral.

Devido a sua importância como restaurador da Ordem, a congregação brasileira, que hoje existe graças a ele, constituiu uma comissão para a comemoração do seu centenário de morte. Dentro deste contexto, surgiu a proposta de se dar a conhecer documentos relativos a frei Domingos e a Restauração que, até então, eram de acesso restrito aos monges da congregação, visto que todos os documentos pessoais dos monges e aqueles relacionados diretamente à Ordem, têm como regra serem guardados nos arquivos dos mosteiros, que, em geral, se encontram na clausura.

Desta forma, os sermões cuja edição aqui se propõe, foram transcritos e editados de forma conservadora, em edição semidiplomática em publicação conjunta pelos mosteiros de São Bento da Bahia e do Rio de Janeiro. No entanto, devido à importância de frei Domingos e a beleza de seus textos, surgiu, por parte dos religiosos da congregação e pessoas próximas à Ordem (oblatos, religiosos de outras ordens e do clero secular) a demanda de que se publicassem tais textos sem as marcas de edição, que "atrapalham a leitura". Assim, à semelhança de outros trabalhos que já se vêm realizando com documentos do Arquivo do Mosteiro da Bahia, como o Dietário das vidas e mortes os monges, pretende-se preparar, com critérios rigorosos, uma edição que tem como alvo o público leigo.

Além da importância histórica de dom frei Domingos da Transfiguração Machado, estudar seus manuscritos pode revelar dados linguísticos dos séculos XIX e XX que contribuam, de alguma forma, para os estudos de linguística histórica.

Para iniciar esse estudo pretende-se analisar os Sermões "Sobre o escândalo", "Sobre a maledicência", "Paixão", "Sermão da Misericórdia", "São Sebastião" e "Nossa Senhora de Montserrat" por 
acreditar que eles trazem em seu discurso uma rica argumentação sobre os costumes da época, os modos de agir, de pensar, as ideologias, pois, segundo Amado (1997), os sermões têm "[...] um poderoso impacto histórico e emotivo [...]", são eficientes em formar opiniões, podendo esse texto caracterizar os pensamentos de uma época, pelo prisma da igreja baiana.

Acredita-se que essas informações podem trazer novos dados linguísticos, além de fatos históricos, contribuindo, assim, para um maior conhecimento da história do Brasil e da Congregação Beneditina Brasileira.

\section{Métodos ou técnicas de observação previstas}

Todos os documentos que serão objeto desta pesquisa já foram inicialmente selecionados, digitalizados, transcritos e editados (LOSE et al., 2009). A etapa seguinte constituir-se-á da análise detalhada da escrita dos textos para elaboração de critérios para edição que se pretende apresentar.

Concomitantemente, far-se-á a leitura do material teórico selecionado até o momento e a busca por mais informações a respeito de critérios e métodos de edições modernizadas.

O trabalho de "construção" da versão "limpa" do texto terá, principalmente, como escopo os critérios utilizados por Lose (2005) em sua tese de doutorado, na qual esboços e rascunhos do poeta baiano Arthur de Salles foram apresentadas no que seria uma "versão final" dos documentos, a partir da qual se remetia (através de hyperlinks) às versões anteriores e realmente existentes do texto em uma edição em formato digital.

A edição completa constituir-se-á de um levantamento biográfico do autor, da descrição dos documentos, dos critérios de transcrição e apresentação dos textos, da transcrição semidiplomática destes, seguida de sua edição "depurada". Além do mais, acompanharão o estudo, um levantamento e análise do discurso do texto utilizado nos documentos, além de um DVD contendo os fac-símiles em formato digital dos manuscritos. 
Para a edição depurada, alguns dos critérios abaixo poderão ser utilizados:

- Para cada texto reconstituir-se-á o que teria sido a última versão deixada pelo autor. Esta última versão respeita com fidelidade os movimentos de escrita do autor, mesmo nos casos em que se pode interpretar uma intenção outra, um pouco diversa daquela que se encontra graficamente representada no documento. Em função de os documentos editados trazerem majoritariamente textos em processo de criação, o que se obterá como resultado dessa "última versão" nem sempre parecerá ter nexo dentro do que se espera de um texto definitivo. A decisão de interferir no "conteúdo" do texto será tomada a cada caso.

- Mesmo pertencendo a mais de uma campanha de escritura, todos os movimentos de escrita serão remetidos a um único documento (a "última versão").

- As linhas que foram inteiramente anuladas pelo autor serão suprimidas do texto da última versão.

- Grafos aleatórios não serão considerados na reconstrução da última versão.

A análise linguística será voltada para um breve estudo da língua no que tange ao discurso, utilizando para isso referências pertinentes da área.

\section{REFERÊNCIAS BIBLIOGRÁFICAS}

AMADO, Teresa. Os géneros e o trabalho textual. In: RIBEIRO, Cristina Almeida; MADUREIRA, Margarida (coord.). O género do texto medieval. Lisboa: Cosmos. 1997.

AMARAL, Dom Emanuel d'Able do, OSB. Introdução à história monástica. Salvador: São Bento, 2006.

ANDRADE, Marla Oliveira; LOSE, Alícia Duhá. Pesquisas filológicas nos acervos da Biblioteca Histórica do Mosteiro de São Bento da Bahia. Scripta Philologica. Salvador, n. 3, 2007. CD-ROM. 
AUERBACH, Erich. Introdução aos estudos literários. Trad. de José Paulo Paes. São Paulo: Cultrix, 1972.

AZEVEDO FILHO, Leodegário de Azevedo. Iniciação em crítica textual. Rio de Janeiro: Presença, 1987.

BARBOSA, Dom Marcos, OSB. Os beneditinos na Europa e no Brasil. In: ALMEIDA, Dom Emanuel, OSB. 400 anos do Mosteiro de São Bento do Rio de Janeiro. Rio de Janeiro: Lumen Christi, 1991, p. 4-8.

BERWANGER, Ana Regina; LEAL, João Eurípedes Franklin. Noções de paleografia e de diplomática. 2. ed. Santa Maria: EDUFSM, 1995.

BETTENCOURT, Dom Estêvão, OSB. A restauração dos mosteiros beneditinos do Brasil em fins do século XIX. In: ALMEIDA, Dom Emanuel, OSB. 400 anos do Mosteiro de São Bento do Rio de Janeiro. Rio de Janeiro: Lumen Christi, 1991, p. 9-20.

CANO AGUILAR, Rafael. Introducción al análisis filológico. Madrid: Castalia, 2000.

ENDRES, Dom José, OSB. Catálogo dos bispos gerais, provinciais, abades e mais cargos da Ordem de São Bento do Brasil (15821975). Salvador: Thipografia Beneditina, 1976.

KUNG, Hans. Igreja Católica. Rio de Janeiro: Objetiva, 2002.

LOSE, Alícia Duhá. Arthur de Salles: esboços e rascunhos. Salvador, 3 v. il + 1 CD-Rom. Tese (Doutorado em Letras e Linguística) Programa de Pós-Graduação em Letras e Linguística da Universidade Federal da Bahia, 2004. Orientação Prof ${ }^{a}$ Dra. Célia Marques Telles.

LOSE, Alícia Duhá; PAIXÃO, Dom Gregório; SANDES, Anna Paula; SANCHES, Gérsica. Dietário (1582-1815) do Mosteiro de São Bento da Bahia: edição diplomática e estudo filológico. Salvador: Mosteiro de São Bento; Eudfba, 2009.

LOSE, Alícia Duhá et al. Sermões de frei Domingos da Transfiguração Machado: o Restaurador da Congregação Beneditina Brasileira. Salvador; Rio de Janeiro: Edições São Bento; Lumen Christi, 2009. $159 \mathrm{p}$. 
LOSE, Alícia Duhá; CARVALHO, Dom Adriano de Araújo. Acervo documental de frei Domingos da Transfiguração Machado - O restaurador da ordem beneditina no Brasil: proposta de edição, análise linguística e contextualização histórica e teológica. Niterói, III Encontro Internacional de filologia, 2008. (comunicação inédita)

LUNA, Dom Joaquim G. de, OSB. Os monges beneditinos no Brasil: esboço histórico. Rio de Janeiro: Lumen Christi, 1997.

SCHERER, Dom Michael Emílio, OSB. Frei Domingos da Transfiguração Machado. Rio de Janeiro: Lumen Christi, 1980.

SPAGGIARI, Barbara; PERUGI, Maurizio. Fundamentos da crítica textual. Rio de Janeiro: Lucerna, 2004.

SPINA, Segismundo. Introdução à edótica: crítica textual. 2. ed. rev. e atual. São Paulo: Ars Poetica; EDUSP, 1994.

TELLES, Célia Marques. Mudanças linguísticas e crítica textual. Estudos Linguísticos e Literários, Salvador, n. 25/26, p. 91-119, jan.dez. 2000. 